\title{
Optimization of water flushing in lowland urban river in Jiaxing, Zhejiang using dissolved oxygen as the indicator
}

\author{
Peiying Tan ${ }^{1, \text { a }}$, David Z. Zhu ${ }^{1,2}$, Yiping Zhang ${ }^{1}$ and Yongchao Zhou ${ }^{1}$ \\ ${ }^{1}$ Department of Civil Engineering, Zhejiang University,310027 Hangzhou, china. \\ ${ }^{2}$ Department of Civil and Environmental Engineering, University of Alberta, T6G 2W2, Edmonton, AB, Canada.
}

\begin{abstract}
River flushing has been considered as an effective tool for improving water quality in heavily polluted urban rivers. Dissolved oxygen (DO) as the evaluation index of water quality varied with time during and after water flushing. The time intervals between the flushing should be optimized such that the DO concentration remains above $2 \mathrm{mg} / \mathrm{L}$ in the river. The duration between the flushing was found to be mainly correlated to the water temperature and the saturation level of dissolved oxygen. For the study river, when the temperature was below $15{ }^{\circ} \mathrm{C}$, there was an exponential relationship between the duration and saturation level of DO. For instance, the estimated duration was 157 hours or about 7 days for the subsequent flushing when the saturation level of DO was $90 \%$. This duration was no more than 2 days when the temperature was above $15^{\circ} \mathrm{C}$.
\end{abstract}

\section{Introduction}

Water flushing has been widely used as an effective tool for improving water quality in relatively small water bodies such as urban rivers. The role of water flushing mainly depends on the ability in water purification and pollutions dilution in rivers. In order to maintain good water quality of urban river, we had established the guidance of water flushing through research on improving the water quality of urban rivers by using the existing water conservancy facilities in Shanghai. The program of water flushing should include the quantity of water flushing to improve the water quality and the interval between two water flushing event to ensure maintaining good water quality for a long time by starting the water flushing timely.

Dissolved oxygen (DO) determines the metabolism and is a critical index in water quality [1]. The lowland urban river frequently occurs anaerobic phenomenon because of the scarce water supply and the slow movement of water in the river [2]. The decomposition of organic matters in anaerobic conditions release pungent odors and harmful substance which are unfriendly to aquatic animals and human beings. The level of DO concentration in rivers can be used as the evaluation indictor for water flushing. Thus, the variation of DO in the lowland urban river during the water flushing would play an important role in developing the water flushing plan. the interval of water flushing should be standard to avoid anaerobic phenomenon by transferring water timely. We regard $2 \mathrm{mg} / \mathrm{L}$ as a standard value below which the water flushing should be proceeded as most of aquatic animals cannot survive in this situation.
In this study, a field study was conducted in Jiaxing. The river in Jiaxing urban is slow-moving and cut off by many water conservancy facilities. To solve the poor water quality, water flushing was conducted through an existing pump station.

\section{Study site and method}

The river in our study, located at Jiaxing, China, is a typical lowland urban river. The cross sections of the river are mostly trapezoidal and the average width is 20 $\mathrm{m}$ with the narrowest being $6.52 \mathrm{~m}$. The depth of river ranges from $0.6-1.4 \mathrm{~m}$, and the width to depth ratio is between 14 to 33. In this area, water flow is slow (the velocity in urban river is generally less than $0.02 \mathrm{~m} / \mathrm{s}$ ) because of the gentle slope (less than $0.01 \%$ ) and the numerous hydraulic structures such as sluices and pump stations. It is an isolated water system with poor water quality in the river. Thus, water flushing through the existing water conservancy facilities was used to improve the water quality in this area.

The data was collected from long-term online monitoring instruments in the downstream channel cross-section where was 200 meters away from the pump station. YSI6600V2 multi-parameter water quality monitor (YSI Inc., USA) was used to record water temperature, DO concertation and saturation level of dissolved oxygen hourly during November 2013 to November 2015. SonTek-SL1500 side-looking doppler current meters (YSI Inc., USA) monitored river discharge and velocity once an hour during the same time.

Meanwhile the pump station transferred water to the closed river as needed. In these two years period, more

\footnotetext{
a Corresponding author: 18806518458r@163.com
} 
than 30 water flushing events occurred. In this study, we chose 30 well-documented events to analyze the water quality variation. The statistical analysis was performed on IBM SPSS (Statistic Package for Social Science) software to conclude the correlation of related parameters.

\section{Data analysis and discussion}

Hourly data collected from the online instruments (Fig.1) simply shows the variation of temperature $(\mathrm{T}), \mathrm{DO}$ and river discharge $\left(\mathrm{q}_{0}\right)$. The variation of river discharge occurred frequently and rapidly. At the same time, the concentration of DO in water varied sharply. Through the DO trend in this 2-years period, we found that the lowest value of DO in winter exceeded the values of DO in other seasons which approached to 0 .

A complete water flushing event could be divided into four periods (Fig.2). The first period (I) included the whole process of water transferred through the pump station. The concentration of DO increased instantly as the river discharge of the river section built up. Then the concentration dropped continuously until the next variation of the river discharge occurred. The remaining three stages (II, III, IV) made up the time duration of DO remaining above $2 \mathrm{mg} / \mathrm{L}$ after the water flushing. In II stage, the concentration of the DO was higher in overall and the river discharge remained slight fluctuation. Meanwhile, DO experienced a linear descent with time. Compared to stage II, the concentration of DO and the temperature were at a lower level in stage IV. The concentration of the DO maintained a slow downward trend with small daily variations in stage IV. Flow changed in the opposite direction occurring in stage III and the DO concentration increased indicated that larger flow variation may result in the value of DO concentration increasing. This view was consistent with previous study [3], one of the explanations was that the flow fluctuation increased the reaeration coefficient by enlarging the air entrainment in the river surface.

During the two years, 30 well-documented water flushing events were counted (Table 1). We paid our attention on those factors including discharge of water flushing $\left(\mathrm{q}_{0}\right)$, duration length of water flushing $\left(\mathrm{t}_{\mathrm{d}}\right)$, total water quantity of water flushing(V), temperature (T), DO concentration at water flushing ending time, saturation level of dissolved oxygen (DO Sat.) at the water flushing ending time, and time duration when DO concentration remained above $2 \mathrm{mg} / \mathrm{L}(\mathrm{H})$. As water temperature varied seasonally, we divided the $\mathrm{T}$ data into low-temperature season $\mathrm{A}\left(\mathrm{T}<15^{\circ} \mathrm{C}\right)$ and high- temperature season $\mathrm{B}(\mathrm{T}>$ $\left.15^{\circ} \mathrm{C}\right)$.

The average temperature in season A was $9.13^{\circ} \mathrm{Cand}$ corresponding the value in season $\mathrm{B}$ was $25.63^{\circ} \mathrm{C}$. Concerning to $\mathrm{H}$, the mean value in season $\mathrm{A}$ was greater than the mean value in season B with large standard deviation. In overall, the value of DO concentration in season A was larger than it in season B. As the saturation of DO concentration in water increased with temperature decreasing, even the same value of DO concentration corresponded to different saturation levels of oxygen in different season. 


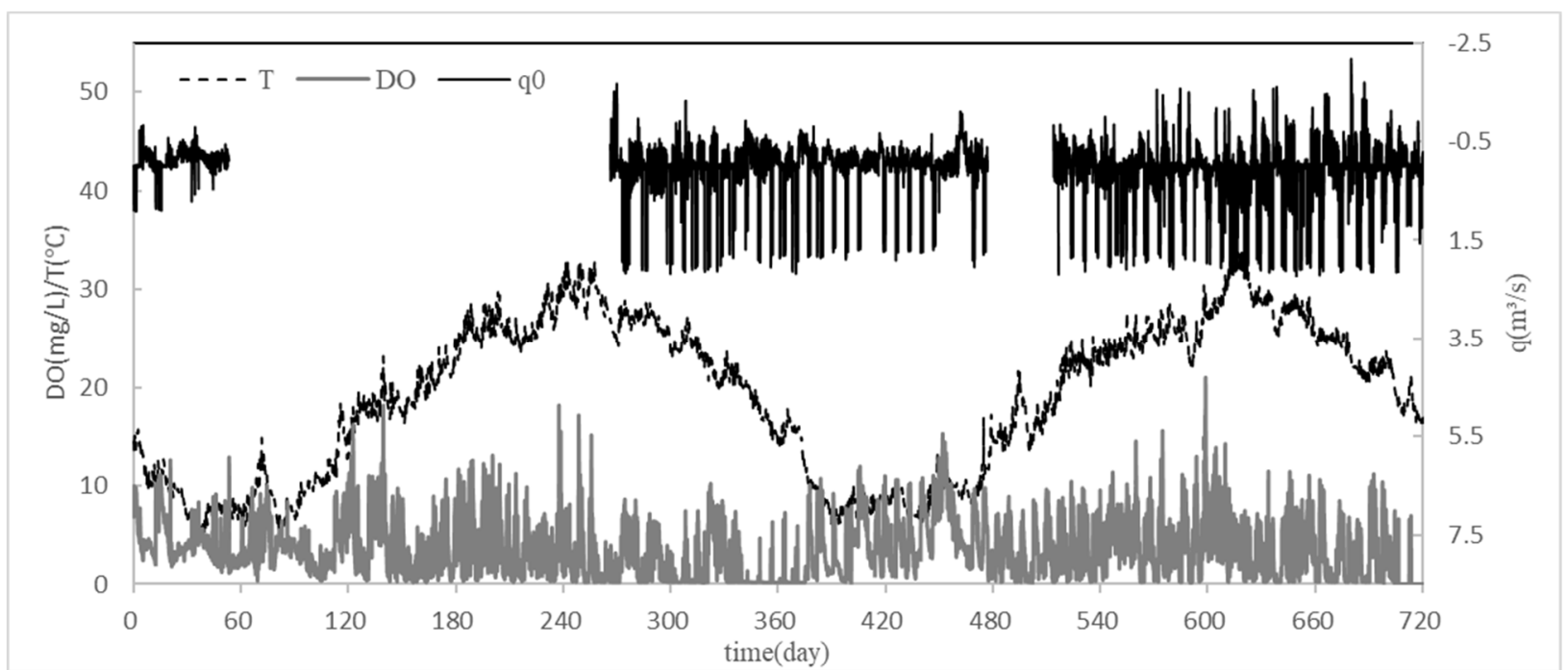

Figure 1. Evolution of hourly data in river discharge $\mathrm{q}_{0}\left(\mathrm{~m}^{3} / \mathrm{s}\right), \mathrm{DO}(\mathrm{mg} / \mathrm{L})$, temperature $\mathrm{T}\left({ }^{\circ} \mathrm{C}\right)$ from 0:00 November 22,2013 to $0: 00$ November 13 2015. The data of river discharge was missing from 10:00 January 14,2014 to 16:00 July 16, August 2014 and 19:00 March 15, 2015 to 16:00 April 21,2015. Backflow often occurred due to the impact of water conservancy facilities in the upstream of

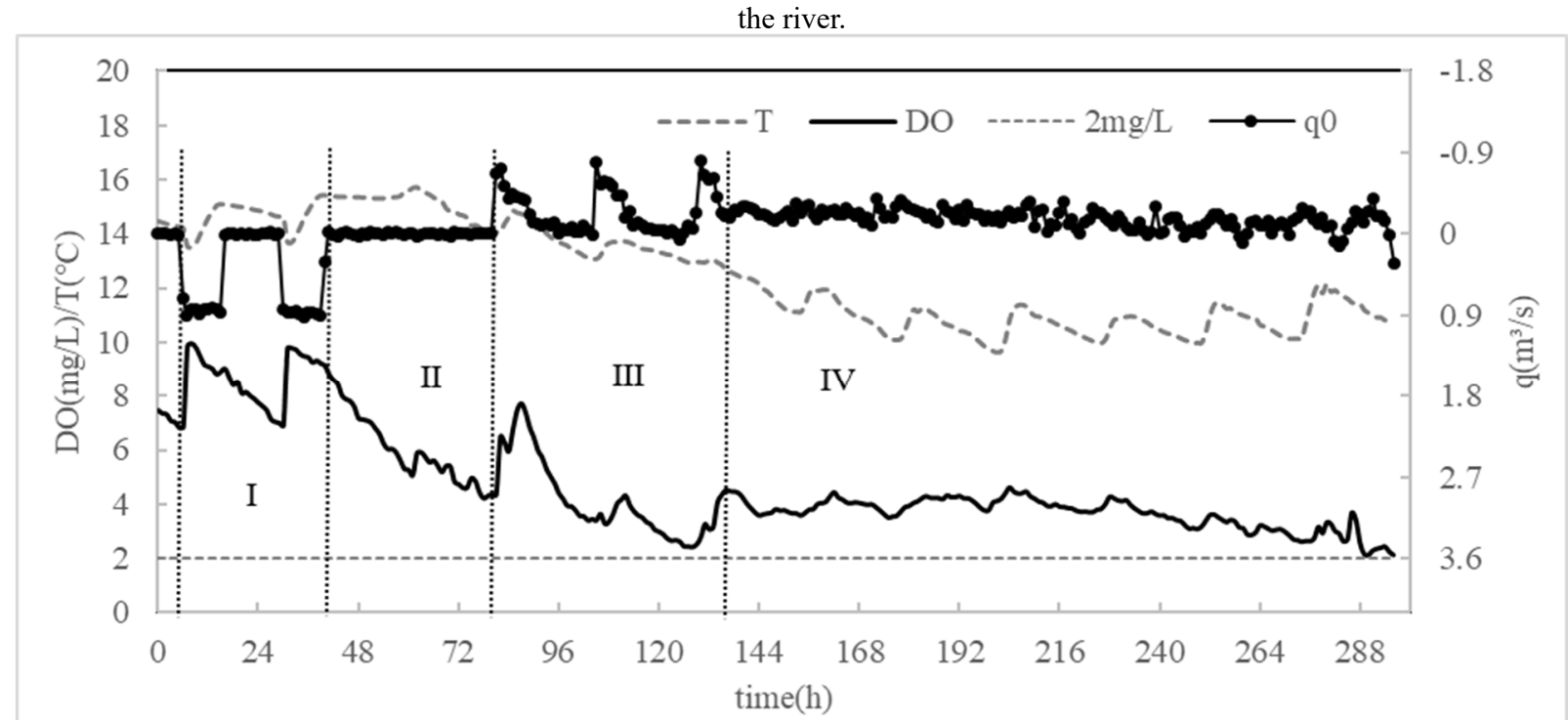

Figure 2. Evolution of hourly values in river discharge $\mathrm{q}_{0}\left(\mathrm{~m}^{3} / \mathrm{s}\right), \mathrm{DO}(\mathrm{mg} / \mathrm{L})$, temperature $\mathrm{T}\left({ }^{\circ} \mathrm{C}\right)$ during a water flushing event from 0:00 November 22, 2013 to 8:00 December 4, 2013.

In order to investigate factors influencing the time duration $\mathrm{H}$, we analyzed the matrix scatter diagrams (Fig.3). For season A, there was a clear exponential relationship between $\mathrm{H}(\mathrm{h})$ and DO Sat. (\%). By contrast, each of factors in season B had a very messy relationship with $\mathrm{H}$. There wasn't a clear relationship between the remaining factors, except for the mathematical relationship between DO and ODO $\%$ or between $\mathrm{q}_{0}, \mathrm{t}_{\mathrm{d}}$ and $\mathrm{V}$. 
Table 1. Statistical description of 30 well-documented water flushing events depending on the season A and season B

\begin{tabular}{|c|c|c|c|c|c|c|c|c|}
\hline & & $\mathrm{T}\left({ }^{\circ} \mathrm{C}\right)$ & $\mathrm{q}_{0}\left(\mathrm{~m}^{3} / \mathrm{s}\right)$ & $t_{d}(h)$ & $\mathrm{V}\left(\mathrm{m}^{3}\right)$ & $\mathrm{DO}(\mathrm{mg} / \mathrm{L})$ & DO Sat. (\%) & $\mathrm{H}(\mathrm{h})$ \\
\hline \multirow{4}{*}{$\begin{array}{l}A \\
N=11\end{array}$} & minimum value & 6.91 & 0.85 & 12.00 & 61200 & 8.00 & 72 & 28 \\
\hline & maximum value & 14.39 & 1.82 & 27.00 & 133812 & 11.00 & 94 & 423 \\
\hline & mean value & 9.13 & 1.55 & 15.26 & 81335 & 9.64 & 85 & 138 \\
\hline & standard deviation & 2.17 & 0.35 & 4.77 & 18323 & 0.81 & 8 & 113 \\
\hline \multirow{4}{*}{$\begin{array}{c}B \\
N=19\end{array}$} & minimum value & 20.43 & 0.89 & 14.00 & 60876 & 6.00 & 66 & 10 \\
\hline & maximum value & 32.00 & 1.82 & 39.00 & 216216 & 9.00 & 115 & 79 \\
\hline & mean value & 25.63 & 1.51 & 20.68 & 111500 & 7.42 & 91 & 43 \\
\hline & standard deviation & 3.41 & 0.28 & 6.59 & 41021 & 1.12 & 13 & 18 \\
\hline
\end{tabular}

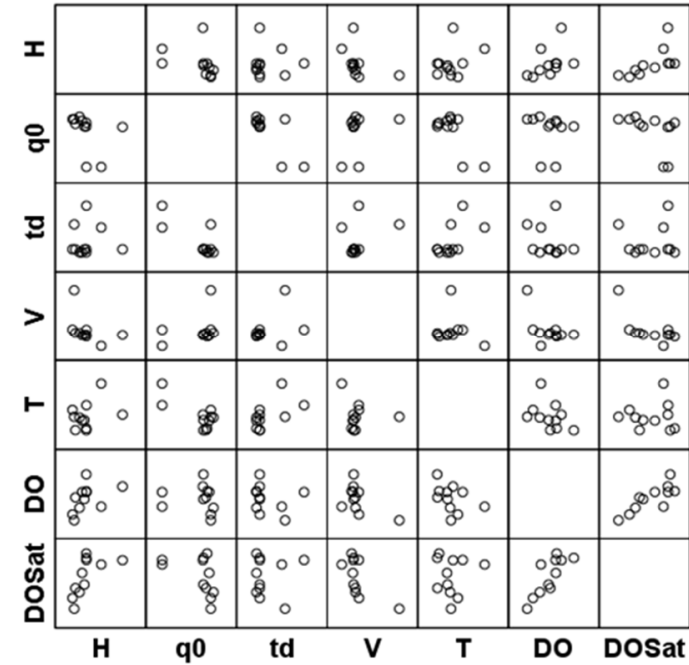

(a) Season A

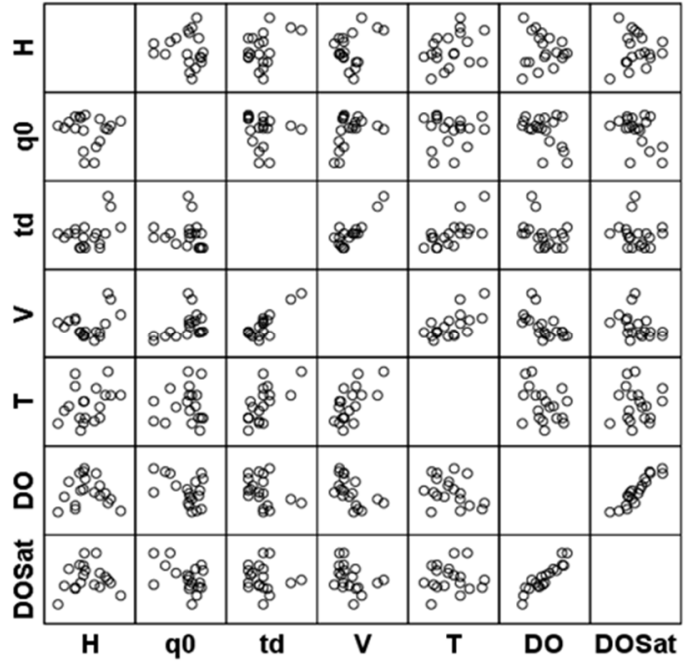

(b) Season B

Figure 3. Matrix scatter diagram between duration when DO concentration remained above $2 \mathrm{mg} / \mathrm{L}$, water flushing $\left(\mathrm{q}_{0}\right)$, the duration of water flushing $\left(\mathrm{t}_{\mathrm{d}}\right)$, the total water quantity of water flushing $(\mathrm{V})$, the concentration of DO at the water flushing ending time, the saturation level of dissolved oxygen (DO Sat.) at the water flushing ending time.

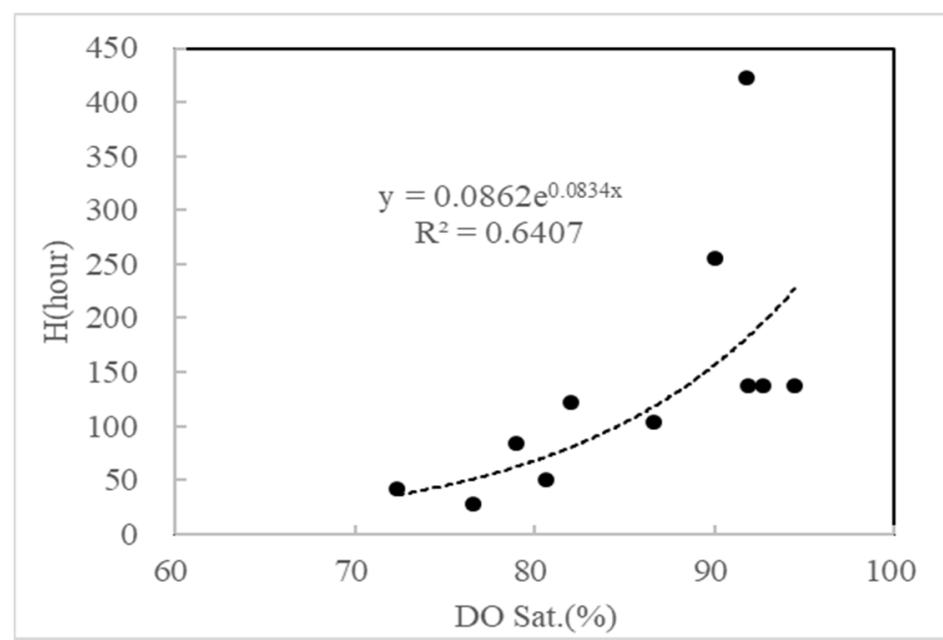

Figure 4. Relation curve between the time duration $(\mathrm{H})$ and the saturation level of dissolved oxygen (DO Sat.) in season A. 
Exponential fitting (Fig.4) between the value of DO Sat. and $H$ in season $A$ got the coefficient of determination $\mathrm{R}^{2}$ ( $\mathrm{R}$ was correlation coefficient) which reached 0.6348. Therefore, we could get a conclusion that the duration $\mathrm{H}$ increasing by the value of DO Sat $\%$.

\section{Conclusions}

The purpose of this research is to find an optimization way to arrange the water flushing in Jiaxing lowland urban river. Concentration of DO representing water quality increases instantly after water flushing, and the length of duration when DO concentration remains above $2 \mathrm{mg} / \mathrm{L}$ varies in different water flushing event. It should be suggested that a new water flushing should begin to maintain the aquatic plants and animals surviving condition when the concentration of DO is below $2 \mathrm{mg} / \mathrm{L}$. In overall, the interval of water flushing should be shortened as temperature rise. The time interval between two water flushing events at high temperature condition should not be more than 2 days because the mean value of
$\mathrm{H}$ in season $\mathrm{B}$ is 43 hours. Corresponding, the time interval between two water flushing events at low temperature condition could get a rough estimation from the value of DO Sat\% by an exponent relationship.

\section{Acknowledgements}

This study was funded by the National Water Pollution Control and Treatment Science and Technology Major Project of China (Grant No. 2011ZX07301-004).

\section{Reference}

1. A. Rajwa-Kuligiewicz, R.J. Bialik, P.M. Rowiński, J. Hydrol. Hydromech., 63, 353 (2015)

2. B.A. Cox, Sci. Total Environ., 314 (2003)

3. N. Thyssen, M. Erlandsen, E. Jeppesen, C. Ursin, Int. Rev. Hydrobiol., 72, 405 (2010) 